\title{
MINUCIAS Y SUTILEZAS DEL EXAMEN EN EDUCACIÓN. IMPACTO SOCIOPSICOPEDAGÓGICO
}

\author{
José Ruiz Ortega \\ Coordinación de Educación Media Superior y Superior. Secretaría de Educación y Cultura, México
}

\section{ANTECEDENTES}

Desde épocas remotas, los preceptores, profesores o autoridades, han manifestado el interés de evaluar el grado de conocimientos que los estudiantes van adquiriendo en su paso por la escuela (Díaz, A., 1993, 1994, 1999, Piña, J., 2000). En este sentido, se ha buscado la forma de hacerlo de manera objetiva; sin embargo, como el aprendizaje no puede ser palpado, olido o visto en su esencia pura ${ }^{1}$, tiene que ser inferido de una forma tal que a la vez permita medirlo y darle seguimiento en función de su evolución, situación que conllevó y conlleva aún un nuevo conflicto, idear y desarrollar una modalidad para evaluar ese proceso, que fuese totalmente neutral y que no sea permeado por las cuestiones de la subjetividad humana. Así surge el EXAMEN con fines de evaluación en la EDUCACIÓN

Con esa finalidad se diseña el examen oral o escrito como el instrumento principal para la evaluación educativa que, con el tiempo se emuló por la mayoría de los sistemas educativos de los países del mundo, tal vez por carecer de elementos teóricos y metodológicos que les permitieran realizar una verdadera apreciación de la evolución del proceso de formación, información y capacitación de sus educandos. La escuela mexicana, ofrece en el currículum formal el examen (oral y escrito) y las calificaciones como resultado de ello, siendo la forma válida y legítima para evaluar y objetivar el aprendizaje (Granja, J. 1988), convirtiéndose en lo que se denomina mandato social e institucional, a tal grado, que el docente ha sumado, entendido y aplicado dentro de su propio capital cultural (Sandoval, E. 2001), que no es menester desarrollar grandes esfuerzos para ser imparcial y neutro a la hora de aplicar sus exámenes, que solamente basta con que quede dentro de los parámetros normales que el imaginario social ha construido y considerado como lo que no se debe cuestionar o porque está dentro de la norma y la normalidad, es decir; parafraseando a Castoriadis (1988), es lo instituido, aunque puede, y a veces sucede, ser instituyente, pero cuando se norma vuelve a lo instituido, aunque en el interior del proceso haya enormes lagunas de entendimiento y comprensión del impacto que pueden ocasionar en el individuo, como ser ontológico y sociológico dichas prácticas de examinación, no sólo en su presente, sino para el futuro.

\section{Tres escenarios distintos y sus similitudes}

Parece ser que para evaluar, juzgar o determinar los conocimientos que un sujeto posee, al finalizar el período escolar, las instituciones educativas sólo disponen de los resultados de los exámenes, ya sea el examen de admisión para el ingreso a un nivel superior o el examen de oposición para un empleo, postulando con ello, según crítica de Jeant Piaget “...que el éxito en los exámenes constituye una prenda de adquisición duradera" ${ }^{2}$, haciendo caso omiso de lo que queda en el subconsciente del ser humano y sus

\footnotetext{
${ }^{1}$ Rivas, J. \& Ruiz, J. (2003). "Las calificaciones, ¿control, castigo o premio?”. Revista Iberoamericana de Educación, OEI, (31).

${ }^{2}$ Piaget, J. (1999). Psicología y pedagogía. 10ª reimpresión, México, Ariel, p.14.
} 
consecuencias al hacer uso de estas prácticas de examinación académica, incluso, antes, durante y después del fenómeno.

Con el objeto de profundizar un poco más sobre la idea, en primer lugar, se exponen tres casos, que sin duda habrá muchos otros que han quedado ahí, en el anonimato, en lo que se sabe pero no se dice, en lo que se cuestiona desde lo oculto sin ser oculto como opina Jurgo Torres Santomé (1998), y en segundo, se pretende hacer una reflexión analítica de los constructos emanados de los mismos, apoyándose en algunos teóricos.

\section{Escenario uno}

"...Jason H., Brillante alumno del segundo curso de una escuela secundaria de Coral Springs, Florida, estaba obsesionado con la idea de ingresar en la facultad de medicina... soñaba con Harvard... su profesor de física, le había dado una puntuación de ochenta en un examen. Convencido de que la nota...ponía en peligro su sueño...fue a la escuela con un cuchillo de cocina $y$, después de enfrentarse a Pologruto... se lo clavó en el cuello. Un juez declaró a Jason inocente...un panel de cuatro psicólogos y psiquiatras afirmó que...había sufrido una psicosis. Jason afirmó que había pensado suicidarse debido a la nota del examen...Creo que él intentaba matarme a mí con el cuchillo" porque estaba furioso por la mala nota",

\section{Escenario dos}

“...En junio del 2004...misma historia del 2003...alumnos rechazados en la facultad de medicina...conflicto entre...estudiantes y las autoridades universitarias...al saludarla, fue notoria en la alumna una expresión que estaba apesadumbrada...su semblante y expresión reflejaban de alguna manera toda la rabia, impotencia, decepción o frustración que emanaba desde lo más hondo de su ser... se le sugirió que analizara otras opciones... a lo que contesta casi con odio, "si no entro a Medicina no me interesa ninguna otra. Mejor no hago nada"...en esa negación se veía la presencia del fracaso reciente de haber reprobado un examen, su acento era de desprecio hacia sí misma...el responsable contestó: "La política nacional es evitar que ya no existan tantos médicos...que ingrese a la...Tecnológica... la Universidad no tiene la capacidad para... todos...que solicitan el...ingreso...tenemos que hacer una selección de los más aptos... es una política de Estado ...son las minucias y sutilezas...garantizar que ingresen los que serán excelentes médicos y el examen de admisión es por lo pronto el medio más fácil y rápido de seleccionar...".

\section{Escenario tres}

"Una sola vez en la vida quedé paralizado por el temor. Fue durante un examen de cálculo durante mi primer año en la facultad.... Aún recuerdo el aula donde entré esa mañana primaveral, con el mal presentimiento de que iba camino del fracaso... Mientras abría la cubierta azul de mi libreta de examen, sentí el sabor de la ansiedad en la boca del estómago... Pasé toda la hora mirando fijamente la página, mientras pensaba obsesivamente en las consecuencias que tendría que soportar. Los mismos pensamientos se repitieron una y otra vez, en un torbellino de temor y estremecimiento... Lo que más me afectó de ese espantoso momento fue lo limitada que quedó mi mente... Simplemente me concentré en el terror y esperé que aquel tormento terminara...Ese relato del tormento provocado por el pánico me pertenece; hasta el día de hoy representa para mí la prueba más convincente del impacto devastador que el trastorno emocional tiene sobre la claridad mental' ${ }^{5}$.

Tratar de explicar, interpretar o traducir un hecho social para comprenderlo en su dimensión más próxima posible, resulta altamente complejo, "Ya que el individuo que se piensa a sí mismo, es en realidad una abstracción teórica, y el abordaje del sujeto es la aproximación conceptual al ser humano que no es auto-constituido, sino que tiene que pasar por la mirada del otro que lo constituye...el propio Freud hablará

\footnotetext{
${ }^{3}$ Goleman, D, (1997). La inteligencia emocional.5ª reim. México, Vergara editores, S.A. p. 53

${ }^{4}$ Este relato fue escrito por José Ruiz Ortega, tal cual lo presenció como actor directo del mismo. Zacatecas, México a 2 de junio del 2004.

${ }^{5}$ Goleman, op. cit., p. 103.
} 
de la constitución del aparato psíquico en referencia a como simboliza y reprime la vivencia con lo externo, con los otros; que siempre son simbolizados. De forma que en toda psicología hay una referencia a lo social, a lo contextual, y viceversa"6.

Con la finalidad de explicar las razones actitudinales de los actores en los tres escenarios, se intentará hacer una reflexión analítica, tomando como referencias implicaciones psicológicas, sociológicas y pedagógicas, aunque para la finalidad de este trabajo solamente se abordaran las cuestiones psicológicas.

\section{IMPLICACIONES PSICOLÓGICAS}

Desde el punto de vista de la psicología, entendida ésta como la disciplina que estudia la conducta y la experiencia de los seres humanos, de cómo éstos sienten, piensan, aprenden y conocen para adaptarse al medio que los rodea, y particularmente del concepto de psicología social que es aquella que "...se ocupa de los procesos de la conducta, los factores causales y los resultados de la interacción entre personas y grupos" ${ }^{\prime \prime}$, en los tres escenarios expuestos se observa que los estudiantes sufren alteraciones o conflictos emocionales durante y después de un examen con fines de evaluación educativa.

\section{Conflicto emocional}

El término conflicto, alude a la tensión que un individuo mantiene al estar sometido a dos o más fuerzas que se excluyen mutuamente. Para Freud, el conflicto surge cuando las respuestas de comportamiento, necesarias para satisfacer una motivación, no son compatibles con las requeridas para satisfacer otra. Por otro lado, el concepto emoción es un término que se emplea con cierta frecuencia como sinónimo de sentimientos o para designar una reacción que implica determinados cambios fisiológicos. Son tres reacciones primarias que brotan como respuesta inmediata a un estímulo externo, la ira, el amor, y el miedo, que también pueden ser el resultado de un proceso subjetivo, como la memoria, la asociación o la introspección. En palabras de Cortese, Goleman, Smith, Clay y Freud, las emociones han sido el componente psicológico más antiguo del hombre (anterior al lenguaje y el razonamiento), constituyendo la fuerza motora más importante de la conducta del ser humano.

En función de las definiciones anteriores, los estudiantes, según los tres escenarios expuestos en referencia, padecieron un conflicto emocional en sus diferentes momentos, espacios y tiempos, a una situación de examen manifestando ira, frustración, depresión, ansiedad y angustia.

\section{¿Porqué se presenta la ira en los estudiantes?}

Respecto a la ira, Goleman, escribe "...un disparador universal de la ira es la sensación de encontrarse en peligro...que puede estar signado no solo por una amenaza física...sino también, como ocurre con mayor frecuencia, por una amenaza simbólica a la autoestima o a la dignidad: ser tratado en forma injusta o ruda, ser insultado o menospreciado, quedar frustrado en la búsqueda de un objetivo

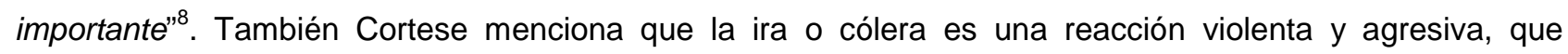
muchas veces se dirige a la causa de la contrariedad, sobre todo cuando hay un peligro inminente, real o

\footnotetext{
${ }^{6}$ Trujillo, D. "De la hermenéutica subjetiva a la hermenéutica del sujeto: hacia una propuesta vincular y conceptual”. EN: Primero, L., (compilador) (2004). Usos de la hermenéutica analógica. México, Primero editores. p.134.

${ }^{7}$ Clay, H. (1982). Introducción a la psicología social. 4ª reimpresión, México: Trillas, p. 20

${ }^{8}$ Goleman, op. cit., p. 103.
} 
imaginario. Para este investigador la ira está íntimamente relacionada con los fracasos, frustraciones y conflictos del hombre.

En función de lo anterior podemos decir que en el joven de la escuela secundaria de Coral Springs, al ver en peligro su ingreso a Harvard, la ira llegó a tal extremo, que le ocasionó un trastorno emocional, al grado de agredir al profesor con arma blanca o como él aseveró de suicidarse al percatarse del resultado del examen, el cual, sin duda, no esperaba. Lo interesante del caso es que la causa de la acción violenta era más una amenaza simbólica que real, entonces ¿por qué no fue capaz de controlar su moción?, ¿qué idea se había estructurado en la mente de este estudiante antes de la explosión violenta?, ¿realmente el resultado del examen fue la causa?, ¿había estudiado con ahínco, con alto grado de motivación, para resolver eficientemente el examen y al no lograrlo se frustró? Hay tantas interrogantes como posibles respuestas, sin embargo, lo sobresaliente del caso es que directa e indirectamente el examen mismo jugó un papel preponderante en el desenlace, sobre todo, antes del resultado mismo.

\section{Frustración, ¿qué es y cómo se genera en los estudiantes?}

El ser humano, según Clay, se frustra cuando no logra alcanzar determinado objetivo muy importante para él, trastocando su personalidad de pasiva a violenta, de alegre y socializadora a depresiva.

Mientras en el primer escenario la respuesta a la frustración por no haber logrado el objetivo fue de agresividad violenta hacia el suicidio o intento de asesinato por parte del estudiante, en el caso de la alumna que fue rechazada en la facultad de medicina en el examen de admisión, la respuesta se transformó en tristeza o depresión, que incluso, prácticamente no le interesaba otra posibilidad, probablemente combinando los recuerdos pasados con el suceso ocurrido en su momento presente, según lo establece Piaget al escribir “...el presente afectivo está bien determinado, como lo mostró Freud, por el pasado del individuo, pero el pasado está reestructurado sin cesar por el presente" ${ }^{\prime 9}$. De ahí que la frustración sea un estado emocional de malestar o desagrado, que se produce en el individuo cuando este no logra alcanzar el objetivo deseado. Un alto grado de frustración puede desencadenar violencia o depresión.

\section{Depresión ¿qué es y cómo se manifiesta en el estudiante?}

Smith, Ausubel y Cortese coinciden en que la depresión es un trastorno mental caracterizado por un estado anímico de tristeza a veces exagerada y duradera. El individuo con depresión suele manifestar sentimientos de inutilidad, culpabilidad e incluso ideas recurrentes de suicidio y muerte. La persona deprimida manifiesta sentimientos de tristeza, pérdida de la capacidad para interesarse o disfrutar de las cosas, disminución de la atención y concentración, pérdida de confianza en sí mismo; se hace reproches la mayor de las veces infundados, no muestra esperanza alguna hacia el futuro, manifiesta pesimismo y visión negativa de la propia vida.

Para el caso de los dos primeros escenarios, parece ser que estas emociones fueron propiciadas interna y externamente a ellos mismos, en función de su personalidad. Pero también, y es lo que no se dice en las narraciones, cada uno de los estudiantes del escenario uno y dos, forzosamente, después de conocer el resultado del examen tuvieron que enfrascarse una lucha interna, que para el segundo caso se subsumió en la depresión; no así para el primero en donde la idea de suicidio estuvo presente. Otra

\footnotetext{
${ }_{9}^{9}$ Piaget, J. (1996). Estudios de psicología genética. 10ª impresión, Argentina: EMECÉ EDITORES, p. 47.
} 
cuestión, aunque no es explícita como en el tercer caso, la ansiedad fue otro sentimiento emocional presente antes, durante y después del fenómeno mismo.

\section{Ansiedad y angustia en los estudiantes ¿por el examen?}

El concepto ansiedad es uno de los temas de mayor énfasis entre los teóricos de la psicología, por considerarla como el conflicto emocional del cual derivan otros conflictos, como los antes expuestos. De acuerdo con Ausubel, Freud, Smith, Clay, Cortese, Perls, Bower, entre otros; la ansiedad es un estado emocional desagradable, un incremento de tensión al yo, que lo motiva para sortear el peligro. Es una tendencia a responder con temor ante una situación que es percibida como amenaza potencial a la autoestima. Por ejemplo, "...se genera ansiedad en los estudiantes de medicina cuando estos se enfrentan a exámenes importantes que amenazan la consecución de una meta vital...se suscita ansiedad durante los períodos de transición del desarrollo de la personalidad, como la adolescencia...los sentimientos de hostilidad pueden generar ansiedad...los sentimientos de culpa...exponiendo al individuo a un retrato deshonroso y reprensible de sí mismo, en desacuerdo con los valores morales que haya interiorizado...la ansiedad es instigada por una amenaza objetivamente peligrosa para la autoestimación" ${ }^{\text {"10 }}$. También, en las personas propensas a experimentar una fuerte ansiedad a ser evaluadas, su capacidad de respuesta a las pruebas disminuye considerablemente. La vivencia fundamental es de miedo, ya sea a la propia situación del examen o a las consecuencias del mismo. En esa situación de ansiedad, el alumno imagina que lo reprobarán en el examen y por tanto, las posibilidades de ser excluido o expulsado lo ponen todavía más ansioso, hasta el grado de autodescalificarse, pensando que no sirve para estudiar o que el estudio no es útil para él o que, si no pasa dicho examen, no tendrá el reconocimiento, el premio o el trabajo deseado. Según Bower, la ansiedad del alumno durante los exámenes es un ejemplo del temor aprendido ya que "los educadores raras veces piensan en la ansiedad que genera la prueba, los estudiantes saben que ésta es un verdadero problema. Algunos se dejan llevar por el pánico durante los exámenes cruciales: se acelera su ritmo cardiaco, les tiemblan las manos y sus mentes quedan en blanco; interpretan las preguntas del examen de modo completamente erróneo"11.

Además de las afirmaciones de Ausubel, Bower y Cortese, Mirta Bicecci, abona a dilucidar desde otro ángulo, las razones no observables por las cuales los estudiantes reaccionaron de la forma descrita. Bicecci postula que una situación de examen es el desencadenante de una angustia que tiene una estructura y está enmarcada, por situaciones más imaginarias que reales, es decir; la angustia "...Está siempre en relación con el objeto que está aprisionado en el fantasma, el lugar de la angustia es cercano siempre al del fantasma... En eso que hace marco a la angustia aparece algo que estaba mucho más cerca, ese huésped familiar que pasa vertiginosamente a lo hostil ${ }^{\text {,12 }}$.

Esto significa que los estudiantes desde el seno familiar y de las interacciones con el contexto social van formando un esquema fantasmagórico, en el sentido de que tienen que someterse a la voluntad de los otros y que si no aprenden a hacerlo, el rechazo es inminente por parte de quien convive. En el caso de la escuela opera lo simbólico, el estudiante ve al profesor como el opresor fantasmal cada vez que le solicita la demostración de sus saberes vía exámenes orales o escritos. Para algunos estudiantes los exámenes

\footnotetext{
${ }_{11}^{10}$ Ausubel, D., et al (1999). Psicología educativa: Un punto de vista cognoscitivo: 12a reimp. México, Trillas, pp. 383-384,

${ }_{11}^{11}$ Bower, G. \& Hilgard, E. (1998). Teorías del aprendizaje. 6ª reimpresión, México: Trillas.

${ }^{12}$ Bicecci, M. "La angustia y la situación de examen". EN: Díaz, A. (1993). El examen: textos para su historia y debate. México: UNAM, pp. 198-199.
} 
provocan severas crisis, ubicándolos ante el peligro mítico de la angustia que según Aray “...Se acompaña de respuestas psicosomáticas características de la angustia como taquicardia y sudoraciones; en ocasiones desmayos, anorexia o bulimia. En los fumadores, por un aumento de la intoxicación tabáquica. El sujeto, frente a la inminencia del examen, aún sin estar en la situación misma, reacciona con una intensificación de la angustia"13.

En este sentido es claro que tanto el estudiante de secundaria cuya meta era ingresar a la facultad de medicina de Harvard, como la que deseaba hacer su carrera profesional también en medicina, habían estado motivándose para ello y sus expectativas estaban perfectamente definidas y, al no lograr el objetivo al que aspiraban, sus sentimientos emocionales descritos, se invierten hacia lo negativo incluyendo la motivación. Parafraseando a Perls, entre mayor es la expectativa, el sueño o la ilusión de un individuo, mayor será la desilusión cuando no se logra o lo ve en peligro, que puede incluso provocar una regresión de su personalidad hacia un estado de violencia por fuertes descargas emocionales.

Otra situación interesante que emerge del análisis producto de los teóricos, pero que no está explícito en las narraciones, es la cuestión de la motivación, la personalidad, la autoestima y la inteligencia mismas que directa e indirectamente se ven afectadas cuando el estudiante está ante una situación de examen.

\section{Motivación ¿qué es y qué propicia en el estudiante?}

Apoyado básicamente en los textos de Wallon, Ausubel, Smith, Cortese, Goleman y Freud, se puede afirmar que la motivación es un proceso interno del individuo, que influye persistentemente en la conducta del ser humano hacia la consecución de una meta. Es a la vez fuente de actividad y de dirección de esa actividad; es también, la fuerza que regula el envío de energía en una dirección específica con un propósito concreto. La motivación puede provenir de las exigencias de determinada situación, de valores subjetivos, e igualmente de necesidades y deseos; o también de una combinación de ellos. En general se clasifica en motivación intrínseca, extrínseca, biológica y social.

Motivación intrínseca: es aquella motivación que procede del propio sujeto y que lo impulsa a realizar actividades por ser gratas, que le gustan. Las personas con motivación intrínseca son responsables, generalmente buscan el logro a través de los desafíos, por lo común están aprendiendo algo nuevo. Por lo regular estas personas mantienen esta motivación bajo su control y tienen la capacidad para "autorreforzarse". Los investigadores coinciden en la importancia de mantener o de no soslayar la motivación intrínseca en el comportamiento escolar y el funcionamiento cognitivo del alumno, considerando que, es posible que desaparezca por largas temporadas por una fuerte descarga emocional ocasionada por las normas institucionales o por el profesor, entre otros factores.

Motivación extrínseca: es la motivación que procede del exterior, debido a que proviene de un estimulador externo a la persona, ésta tiende a lo fácil, al conformismo, a la seguridad haciendo el mínimo esfuerzo para salir del paso o problema, de igual forma, el individuo con alta motivación extrínseca para realizar cualquier actividad o tarea estará buscando el premio o la recompensa, mientras el estímulo exista estará motivado y hace lo que se le pide. Cuando desaparece el premio la motivación extrínseca se esfuma como por encanto. Dicho de otra manera, esta motivación es extremadamente temporal.

\footnotetext{
${ }^{13}$ Aray, J. "El examen, la neurosis de examen y el examen como factor neurotizante", EN: Díaz, A. (1993). El examen: Textos para su
} 
Motivación biológica: Obedece a la necesidad de satisfacer los requerimientos de alimento, líquidos, aire y sueño.

Motivación social: Es la necesidad de afiliación o apego, la necesidad de logro, ya que la sociedad le da importancia al logro, por tanto el estudiante se esfuerza para obtener buenas calificaciones de tal manera que "El miedo al fracaso se presenta cuando los padres no conceden importancia al rendimiento satisfactorio y en cambio sí castigan el fracaso; $y$ así el niño aprende a temer la posibilidad de fracasar, ${ }^{14}$, lo grave está en que el profesor deja marcas emocionales en el estudiante cuando no cumplió con la expectativa de respuesta en un examen, criticándolo acremente y finalmente, es estimulada por la necesidad de poder: "hay muchos individuos que sienten la necesidad de ejercer control sobre la vida de otros ${ }^{\prime 15}$. Mientras que unos se orientan al triunfo sobre los adversarios, otros buscarán ejercer el poder en beneficio de la comunidad o de la gente.

De acuerdo a esto queda claro como el aspecto psicológico, el sociológico y el pedagógico, estuvieron interrelacionados en los tres estudiantes; muestra también, cómo, la motivación intrínseca, extrínseca y social dependen una de la otra.

\section{¿Qué se entiende por personalidad?}

En Smith, Clay, Ausubel encontramos que personalidad son determinadas pautas de pensamiento, percepción y comportamiento que hacen la distinción característica de una persona, al permanecer relativamente fijos y estables, una vez enraizados profundamente en su interior, distinguiéndolo de los demás. Así mismo la personalidad es un proceso permanente y, para estos autores, no está separada de la conducta y de la interacción con el medio. En suma, la personalidad es una organización integrada por todas las características cognoscitivas, volitivas y físicas de un individuo, tal como se manifiesta a diferencia de otros. Caracterización o arquetipo general de la conducta total de la persona.

\section{¿Qué es la autoestima?}

En términos generales la literatura reporta que la autoestima es la consideración y aprecio que se hace una persona de sí misma, es decir, es la valoración que tiene o se hace la persona a sí mismo, como resultado de un proceso de análisis, valoración, asimilación y acomodación de la información derivada tanto de la propia experiencia, como de la interacción de otros significativos como "compañeros, profesores", la familia y el contexto social.

Para otros investigadores, además de lo anterior, los sentimientos emocionales como ira, frustración, depresión, ansiedad, angustia, motivación, autoestima, y personalidad, de alguna manera, se ven alterados cuando el estudiante, indistintamente del nivel educativo que esté cursando, es sometido a exámenes para evaluar el conocimiento adquirido en los diversos cursos. De entre muchos otros Díaz, Goleman, Torres, Ornelas, se desprenden las siguientes ideas en referencia al tópico de los exámenes, según la narración de los tres escenarios citados al inicio y que también sirven de apuntalamiento a los conceptos tratados y a la explicación de la conducta de los estudiantes, en cada uno de los tres casos.

\footnotetext{
historia y debate: México: UNAM, p. 222.

${ }^{14}$ Smith, R., Sarason, I. \& Sarason, B. (1984). Psicología: Fronteras de la conducta. 2ª edición, México, Harla, p. 358. Traducción José Carmen pecina.

${ }^{15}$ Smith, Op, cit. p. 359.
} 
Desafortunadamente cuando se aplica un examen para determinar el conocimiento adquirido por un alumno, no se analiza si el comportamiento observado, refleja verdaderamente un conjunto de "sucesos internos en el sujeto"; tampoco el examen, vislumbra las dificultades del complejo proceso de pensamiento del estudiante y que, al momento del examen, puedan ser traducidas para encontrar la palabra adecuada y lograr expresarse. Si a esto le aunamos la recreación que hace el alumno de las representaciones simbólicas, que establecen que el éxito escolar es una condición previa del triunfo material y social y que, el resultado del examen es decisorio para ser promovido o aceptado en el inmediato ciclo escolar, el temor, angustia o ansiedad se apoderan de él, limitando su mente hacia un razonamiento ilógico o de inutilidad, máxime, si durante ciclos escolares anteriores, las pruebas de control de conocimientos y aptitudes se abordaron con tensión y desconfianza, en virtud de generalizarse la idea de que, en función de los resultados de dichos exámenes, el estudiante será o no promovido.

Por otro lado, es sumamente difícil que el examen dé cuenta de lo aprendido realmente por el alumno. Tendremos que ser realistas dice Ornelas, "sólo miden (y a veces ni eso) si responden de modo adecuado o no. Esta preferencia, que procede del currículum formal, aporta un contenido negativo, tiene un efecto perverso, ya que acostumbra a los niños a buscar siempre el reconocimiento de otros, sobre todo de los compañeros de clase y de los adultos que lo rodean. No se ambiciona que el niño se acostumbre a valorar lo hecho o lo aprendido por el valor intrínseco de hacerlo o aprenderlo. No se le motiva a que sienta satisfacción interna y a apreciar su propio trabajo" ${ }^{16}$. El examen, independientemente de nuestra voluntad, le crea al alumno la orientación falsa de aprobarlo y no la orientación de lograr los objetivos planteados. Con el examen, el objetivo real de la enseñanza queda sustituido por el falso objetivo de aprobar el examen. De tal manera, que desde que se inicia la aplicación de exámenes con esa finalidad, en el niño se empieza a ver y a hacerse cada vez más notorio un "sentimiento de repulsión hacia la cultura, los libros y los productos culturales en general y (por supuesto, también hacia la institución escolar)...este odio hacia la institución escolar y la cultura encuentra su más significativa manifestación en el fracaso escolar y en la deserción"17.

El análisis de los conflictos emocionales expuestos se ha centrado en los actores de los tres escenarios, sin embargo, es importante hacer hincapié en que, en los tres años de secundaria, los estudiantes en promedio tienen que resolver ciento cincuenta ${ }^{18}$ exámenes y en la preparatoria mínimamente se les aplican doscientos diferentes exámenes, de acuerdo al plan de estudios y el bachillerato elegido, únicamente considerando que cada examen fue aprobado (de lo contrario el número de veces aumenta). Esto quiere decir que entre la secundaria y la preparatoria el estudiante fue sometido a una situación de examen, trescientas cincuenta veces, si a esta cantidad le encontramos la constante como factor común de tres días en los que el alumno sufre de angustia, ansiedad y tensión antes, durante y hasta no saber el veredicto del resultado de dicho examen, significa que en escasos seis años el estudiante padeció mil cincuenta días de estos conflictos emocionales. Prácticamente la mitad del tiempo de permanencia en estos dos niveles educativos sufrió una alteración emocional (lógicamente que algunos con mayor o menor grado que otros). Obviamente, es un período de sobrecargas emocionales enormes, que puede resultar sumamente peligroso para el joven adolescente.

\footnotetext{
${ }^{16}$ Ornelas, C. (2000). El sistema educativo: La transición de fin de siglo. México: CIDE, NF, FCE, p.153

${ }_{17}$ Torres, J. (1998). El currículum oculto. 6ª edición, España: Morata, pp.47-48.

${ }^{18}$ Sandoval, E. (2001). La trama de la escuela secundaria: Institución, relaciones y saberes. México: UPN, Plaza y Valdes editores, p. 300 .
} 
Pero además, si revisamos una muestra de exámenes encontramos que la media aritmética de la cantidad de preguntas contenidas en los instrumentos correspondió a treinta, lo que significa también que los alumnos contestaron diez mil quinientas preguntas o cuando menos las leyeron. Entonces emergen otras interrogantes ¿Estaremos ante un suicidio pedagógico?, ¿será medianamente lógico que un alumno no pueda resolver correctamente un examen de admisión integrado por sesenta o 100 preguntas?, ¿en dónde está realmente el problema?, ¿qué es lo que no encaja en esta cuestión?, ¿será la pedagogía de los profesores?, ¿o el sistema de evaluación orienta al estudiante únicamente a "pasar" por medio de la memorización, que una vez superado el examen se olvida rápidamente?, ¿tendría razón Rousseau cuando decía?:

"Resulta extraño que, desde que se interviene en la educación de los niños, no se haya imaginado otro aparato para conducirlos que la emulación, los celos, la necesidad, la vanidad, la avidez, el vil temor, todas las pasiones más peligrosas, las más prontas a desbandadas, y las más a propósito para corromper el alma, incluso antes que el cuerpo esté formado. A cada prescripción precoz que se intenta hacer entrar a su cerebro, se planta un vicio en el fondo de su corazón, insensatos preceptores piensan hacer maravillas haciéndoles malos por enseñarles lo que es la bondad; y luego nos dicen gravemente: tal es el hombre. Sí, tal es el hombre que habéis formado"19.

Al respecto Ángel Díaz Barriga hace el siguiente cuestionamiento “...La misma práctica de los exámenes no deja de ser una práctica que fomenta la confusión, la ansiedad, la cual, en ocasiones es vivida por el mismo docente como una oportunidad para desquitarse de la falta de atención e interés de los estudiantes; a la vez el examen es una de las causas por las que los alumnos estudian aunque a veces sólo repitan información que no comprenden y que pronto se les olvidará, o bien, se preparan para realizar alguna práctica,20.

Si a la edad de 12 a 18 años el individuo, real o simbólicamente vive en el temor, con angustia o ansiedad por causa de esa gran cantidad de exámenes (que por cierto no es la única causa propiciadora del temor), ¿será medianamente lógico seguir con estas prácticas educativas?, que al parecer, para lo único que sirven, es para "dejar sentir con enorme fuerza y claridad la condición normativa que se juega en la escuela" ${ }^{21}$.

Este sucinto análisis muestra nítidamente como los exámenes utilizados con fines de evaluación tienen tantas minucias y sutilezas encubiertas en las sombras del anonimato, que obviamente no se toman en cuenta por quienes aplican estos instrumentos, ya por desconocimiento o por políticas de estado, pero que, definitivamente, las implicaciones psicológicas, sociológicas y pedagógicas no le son muy favorables a los actores involucrados, indistintamente de quién se trate.

En nuestro caso concreto y apoyado en éstos teóricos se observa como, en el primer escenario, una incorrecta pedagogía de la evaluación, desencadena, primero, un conflicto emocional en un sujeto de escasos 15 años de edad que, sin temor a la equivocación, lo acompañará por el resto de su vida como lo afirmó en su momento Freud, "Todo aquel que ha terminado con el examen de grado sus estudios de

\footnotetext{
${ }^{19}$ Rousseau, J. (2003). Emilio. 19ª edición, España: Biblioteca Edad, p.99. Prólogo de Iglesias, M.

${ }^{20}$ Díaz, A. (1994). Una polémica en relación al examen. Revista Iberoamericana de Educación (5).

${ }^{21} \mathrm{Granja}$, J. (1988). Los procesos formales de legitimación de los aprendizajes escolares: rituales normativos, saberes legítimos, sujetos constituidos: El caso de la enseñanza Tecnológica Agropecuaria del nivel medio superior. México: Trabajo presentado como tesis en el Departamento de Investigaciones Educativas del Centro de Investigación y de Estudios Avanzados del I.P.N., para obtener el título de Maestro en Ciencias, especialidad en Educación, el 22 de marzo de 1998
} 
bachillerato puede testimoniar de la tenacidad con que le persigue el sueño de angustia de que va a ser suspendido y tendrá que repetir el curso"22. segundo, trae aparejado, entre otras cosas un conflicto social de proporciones nada gratas para el resto de los involucrados, familiares, profesores, institución escolar; así como la propia Corte de Justicia de Estados Unidos de Norteamérica. Dicho de otra manera, los errores paradigmáticos de la evaluación educativa son evidentes en este escenario, al omitir el proceso de pensamiento como la estructuración cognitiva del alumno, no sólo desde su motivación interior sino también, desde la motivación que en el contexto social se fue adquiriendo.

En el segundo escenario, también es claro que además del conflicto emocional depresivo ocasionado en la joven, desde el punto de vista pedagógico, cómo la escuela de origen de la alumna, no prepara emocionalmente a sus egresados para responder adecuadamente ante circunstancias adversas, pero también el hecho de que, equivocadamente, creó tal vez en la estudiante, un falso objetivo de aprobar los exámenes con suficiencia sin preocuparse de investigar si realmente estaba aprendiendo o memorizando información. Además, es evidente que los exámenes de admisión aplicados en muchas universidades públicas de México tienen la finalidad de cerrar accesos a los estudiantes por la falta de capacidad para atenderlos.

En el tercer caso, queda perfectamente de manifiesto como esta práctica educativa de los exámenes ocasiona que los alumnos se enfoquen en el problema del examen. Dicho de otro modo, los profesores, inconscientemente, ocasionan, con el uso de este instrumento, que los estudiantes se enfoquen a estudiar para pasar un examen y no para apropiarse del conocimiento, menos para descubrirlo como postulaba Rousseau. Nuestro sistema educativo, afirma Sternberg, "fundamentalmente, crea...reforzando o premiando a los alumnos para que sean listos en los exámenes" ${ }^{\prime 23}$. Este investigador se pregunta ¿qué vale más, la respuesta correcta o el razonamiento?, en el mismo tenor, Nisbet y Shucksmith, señalan "Ciertos cursos sobre habilidades para el estudio, en vez de desarrollar la capacidad de aprendizaje, degeneran en la enseñanza de técnicas para pasar los exámenes" ${ }^{24}$. Para estos autores, los profesores se dedican a enseñar mañas o trucos que no conducen a nada bueno al estudiante.

Por otra parte, y curiosamente, muy pocas de las citas aluden a la inteligencia, si usamos el sarcasmo preguntaríamos en estos términos ¿Por qué los estudiantes hacen cosas tan estúpidas sabiendo que tienen inteligencia?, haciendo referencia exclusivamente a nuestros tres protagonistas de los escenarios, suena ilógico que el estudiante de secundaria haya recurrido al intento de asesinato o suicidio, es incomprensible que la joven con intenciones de hacer una carrera de medicina no valorara otras opciones sumiéndose en un estado de depresión aguda e incluso, que el joven del tercer escenario, haya pasado una hora atormentándose sin hacer nada, ¿Dónde queda la inteligencia y cómo la definen los teóricos? ¿Qué se puede hacer en la escuela, primero para detectar el desarrollo de la misma y segundo para canalizarla adecuadamente y al servicio exclusivo del alumno?

\section{¿Qué es la Inteligencia?}

Para este constructo, si es permitido, se dejarán esbozadas únicamente, tal cual nos las presentan los autores, unas cuantas citas, ya que entre los teóricos e investigadores se continúa discutiendo qué es exactamente la inteligencia, pues se observa que existen ciertas contradicciones en su significado.

\footnotetext{
${ }^{22}$ Freud, S. (1992). La interpretación de los sueños. España: Planeta-Agostini, p. 304.
} 

práctica, ${ }^{\prime 25}$

"...la inteligencia implica un equilibrio en el tratamiento de la información analítica, creativa y

"...constructo de medición que designa un nivel general da capacidad cognoscitiva o de aptitud escolar ${ }^{206}$.

"...la capacidad para resolver problemas, o para elaborar productos que son de gran valor para un determinado contexto comunitario o cultural, ${ }^{27 .}$

"...la inteligencia es la adaptación por excelencia, el equilibrio entre una asimilación continua de las cosas a la propia actividad y la acomodación de esos esquemas asimiladores a los objetos...toda inteligencia es una adaptación; toda adaptación implica una asimilación de las cosas al espíritu, lo mismo que el proceso complementario de acomodación,28.

"En el mundo real, inteligencia significa mucho más que buenas calificaciones escolares; incluye el conocimiento de uno mismo y de la forma de alcanzar la felicidad, las relaciones con los demás y la resolución de problemas pertenecientes al mundo real. La inteligencia engloba las aptitudes artísticas y musicales, la capacidad de leer y trabajar con otras personas en distintas situaciones y el conocimiento de aspectos prácticos, como cocinar un plato o arreglar un grifo. Del mismo modo, engloba otras habilidades, como la atlética, ${ }^{29}$.

"La inteligencia humana no es una realidad identificable. Es un constructo utilizado para estimar o evaluar algunas diferencias conductuales entre las personas: éxitos/fracasos académicos, modos de relacionarse con los demás, proyecciones de proyectos de vida, desarrollo de talentos, notas educativas, resultados de tests cognitivos, etc. Los científicos, empero, no han podido ponerse muy de acuerdo respecto a qué denominar una 'conducta inteligente",30.

"Conjunto de atributos, disposiciones y tendencias que integran a un individuo",31.

En función de estas definiciones ¿Cómo ubicamos a cada estudiante de nuestros tres escenarios? ¿Poco o nada inteligentes?

Atendiendo a las definiciones, a cuál de ellas, nuestros actores de los tres escenarios, saldrían mal librados en cuanto a inteligencia se refiere. Según Goleman, el estudiante de Coral Springs, Florida, se cambió de escuela después del incidente y egresó con honores por el más alto promedio, el actor del tercer escenario hoy en día es Doctor en Psicología y tiene varias publicaciones en su haber. La alumna del segundo caso está recluida en su casa ayudando a su madre en las tareas del hogar, por cierto una familia de muy escasos recursos.

Desde el punto de vista del que escribe, las definiciones sobre inteligencia son creaciones del imaginario social, es un constructo que en los escenarios exhibidos no abona mucho a la explicación. Para Goleman "la inteligencia académica tiene poco que ver con la vida emocional. Las personas más brillantes pueden hundirse en los peligros de las pasiones desenfrenadas y de los impulsos incontrolados ${ }^{\text {,32. }}$.

\section{A MANERA DE CONCLUSIÓN}

Es evidente, que la escuela mexicana en su organización, estructuración y ejecución curricular en sus diferentes niveles tendrá que hacer reflexiones muy profundas, si no desea seguir propiciando conflictos emocionales entre sus niños y jóvenes so pretexto de la evaluación vía exámenes. Por desgracia, el que

\footnotetext{
${ }^{23}$ Sternberg, R. \& Apear, L. (1996). Enseñar a pensar. España: AULA XXI/Santillana, p.18.

${ }^{24}$ Nisbet, J. \& Shucksmith, J. (1986). Estrategias de aprendizaje.. España: AULAXXI/Santillana, p. 26.

${ }^{25}$ Sternberg, Oo. Cit., p.14.

${ }^{26}$ Ausubel, D., et al (1999). Psicología educativa: Un punto de vista cognoscitivo: $12^{a}$ reimp. México, Trillas, p. 510

${ }^{27}$ Gardner, H (1995). Inteligencias múltiples: La teoría de la práctica. España, Paidós, p. 25.

${ }^{28}$ Piaget, J. (1999). Psicología y pedagogía. 10 $0^{\mathbf{a}}$ reimpr. México, Ariel, p. 182.

${ }^{29}$ Williams, W. et al. (1996). La inteligencia práctica: Un nuevo enfoque para enseñar a aprender. España: Aula XXI/Santillana, p. 19.

Traducción de José Ernesto Alberola Blázquez (1999)

${ }^{30}$ Pizarro, R. \& Crespo, N. (1997).Inteligencias múltiples y aprendizajes escolares. Universidad de Chile, Facultad de Ciencias Sociales.

Revista Talón de Aquiles, (5), Primavera.

${ }^{31}$ Smith, Op, cit. p. 861.

${ }^{32}$ Goleman, op. cit. p. 54
} 
sufre las consecuencias de una escuela poco inteligente es el estudiante, al orientársele con falsedad y al dejar de promover o desarrollar su inteligencia entre otras cuestiones.

Se considera necesario profundizar esta reflexión analítica del impacto sociopsicopedagógico de los exámenes en los estudiantes de países como México, obteniendo información de campo con la finalidad de realizar una comparación con los resultados obtenidos en otros países y para plantear alternativas que coadyuven al reenfoque orientador de estudiantes y profesores, circunscrita a cada cultura y condiciones socioeconómicas específicas.

Por otra parte, es importante empezar a reflexionar sobre qué debe hacer la escuela para preparar emocionalmente a los estudiantes, como medidas preventivas de atemperamiento de conflictos emocionales.

\section{BIBLIOGRAFÍA}

AusubeL, D., et al (1999). Psicología educativa: Un punto de vista cognoscitivo: 12ª reimp. México, Trillas.

CASTORIADIS, C. (1988). Los dominios del hombre: las encrucijadas del laberinto. Barcelona: Gedisa.

CLAY, H. (1982). Introducción a la psicología social. 4ª̣ reimpresión, México: Trillas

CORTESE, A. (2004 ). Cómo influyen mis emociones en el estudio y el aprendizaje. http://www.inteligenciaemocional.org/ie en la educación/comoinfluyenmisemociones.htm.

DíAZ, A. (1993). El examen: textos para su historia y debate. México: UNAM.

DíAZ, A. (1994). Una polémica en relación al examen. Revista lberoamericana de Educación (5).

DíAz, A. (1999). Didáctica y currículum: convergencia en los programas de estudio. México: Paidós.

FREUD, S. (1992). La interpretación de los sueños. España: Planeta-Agostini.

FreUd, S. (1975). Obras completas. Ordenamientos, comentarios y notas de James Strachey con la colaboración de Ana Freud, asistidos por Alix Strachey y Alan Tyson. Traducción directa del alemán de José L. Etcheverry. Buenos Aires: Amorrortu editores.

FREUD, S. (1971). Introducción al psicoanálisis para educadores. Buenos Aires: Paidós.

GARDNER, H. (1995). Inteligencias múltiples. España, Paidós.

Goleman, D. (1997). La inteligencia emocional. 5a reimpresión, México. Vergara Editores, S.A.

GRANJA, J. (1988). Los procesos formales de legitimación de los aprendizajes escolares: rituales normativos, saberes legítimos, sujetos constituidos: El caso de la enseñanza Tecnológica Agropecuaria del nivel medio superior. México: Trabajo presentado como tesis en el Departamento de Investigaciones Educativas del Centro de Investigación y de Estudios Avanzados del I.P.N., para obtener el título de Maestro en Ciencias, especialidad en Educación, el 22 de marzo de 1998.

NISBET, J. \& Shucksmith, J. (1986). Estrategias de aprendizaje.. España: AULAXXI/Santillana.

ORNELAS, C. (2000). El sistema educativo: La transición de fin de siglo. México: CIDE, NF, FCE.

PERLS, F. (1985). Yo, hambre y agresión. 2ª reimpresión, México, FCE.

PIAGET, J. (1999). Psicología y pedagogía. 10ª reimpresión, México, Ariel 
PIAGET, J. (1996). Estudios de psicología genética. 10ªimpresión, Argentina: EMECÉ EDITORES.

PIÑA, J. (2000). Zacatecas y Guadalupe, catálogo de tesis de instituciones púbkicas de educación media superior y superior: con un ensayo sobre la historia de la tesis. Zacatecas: UAZ.CEP; IZC-RLV; ENMAC, IZEA.

PizARRO, R. \& CRESPO, N. (1997).Inteligencias múltiples y aprendizajes escolares. Universidad de Chile, Facultad de Ciencias Sociales. Revista Talón de Aquiles, (5), Primavera.

Primero, L., et al. (2004). Usos de la hermenéutica analógica. México: Primero editores.

RIVAS, J. \& RuIz, J. (2003). "Las calificaciones, ¿control, castigo o premio?”. Revista Iberoamericana de Educación, OEI, (31), $11 \mathrm{p}$

Rousseau, J. (2003). Emilio. 19a edición, España: Biblioteca Edad. Prólogo de Iglesias, M.

SANDOVAL, E. (2001). La trama de la escuela secundaria: Institución, relaciones y saberes. México: UPN, Plaza y Valdes editores.

Smith, R., Sarason, I. \& Sarason, B. (1984). Psicología: Fronteras de la conducta. 2a edición, México, Harla. Traducción José Carmen pecina.

STERNBERG, R. \& Apear, L. (1996). Enseñar a pensar. España: AULA XXI/Santillana

WalLoN, H. (1981). Psicología y educación: Las aportaciones de la psicología a la renovación educativa. Madrid: Pablo del Río Editor.

WILLIAMS, W., et al. (1996). La inteligencia práctica : Un nuevo enfoque para enseñar a aprender. España: Aula XXI/Santillana. Traducción de José Ernesto Alberola Blázquez (1999). 


\title{
Contactar
}

Revista lberoamericana de Educación

\author{
Principal OEI
}

